\title{
UNDERSTANDING AND RESPONDING TO PAIN AND PAIN-BASED BEHAVIOUR WITH YOUTH IN AND FROM CARE: PERSPECTIVES FROM THE INSIDE-OUT AND OUTSIDE-IN
}

\section{Lilia M. Zaharieva and James P. Anglin}

\begin{abstract}
This article presents the findings from a dialogical research project involving a young adult student with lived experiences in care (inside-out perspective) and a seasoned child and youth care professional (outside-in perspective), exploring the pain of complex trauma and formulating healing responses to pain-based behaviour. The co-authors identify elements and dynamics related to the healing journey and present their findings largely in conversational format congruent with the process of discovery. Notions of family privilege, shattered assumptions, double distortion, pain and pain-based behaviour, the language of pain, evolution of self, moments of choice, following the yellow brick road, eight stages of healing, and self-compassion are discussed with an emphasis on understanding and responding supportively to the lived experiences of young people in and from care.
\end{abstract}

Keywords: pain-based behaviour, healing, dialogic research, complex trauma

Lilia Zaharieva is a fourth-year student in the BCYC program at the School of Child and Youth Care, University of Victoria, BC, Canada. Email: lmzaharieva@gmail.com

James Anglin PhD (corresponding author) is Professor Emeritus in the School of Child and Youth Care at the University of Victoria, BC, Canada. He can be reached at \#78, 1255 Wain Road, North Saanich, BC, Canada V8L 4R4. Email: janglin@uvic.ca 
International Journal of Child, Youth and Family Studies (2019) 10(2-3): 25-44

This article is constructed using a combination of dialogue and narrative formats, as the material presented evolved over a four-month period involving 13 sessions and more than 25 hours of conversation between the two authors. Late in 2016, Jim was approached to present a three-hour plenary session to open a conference of mental health professionals in Bergen, Norway. When he asked what the theme was, he was told "pain-based behaviour", a notion that Jim had created and published in 2002. Not having explored the notion for a number of years, Jim asked Lilia if she would work as a research associate over a four-month period in order to assist with a more indepth exploration of pain and pain-based behaviour experienced by youth in and from care. We agreed to meet every week for about two hours to engage in an extended dialogue about our experiences, and about our responses to selected readings related to pain and pain-based behaviour that we would read in advance. What follows includes a blend of actual elements of dialogue and some paraphrasing of more extended exchanges.

We have been urged by colleagues to retain the informal and conversational approach we took in this research, so we have attempted to reflect the dialogical spirit of the process as well as capture some of our major insights and findings more or less as they happened. We have inserted into our dialogue the key references that we drew upon, for readers who may wish to do followup reading.

The research method we used has been called "dialogical research" (Frank, 2005) or “dialogic inquiry" (Denzin \& Lincoln, 1994, 101-102). Such a qualitative approach provides an opportunity for in-depth exploration of a phenomenon through the lived experiences of the two dialogue participants. In this instance, it became a reciprocal exploration resulting in joint analyses and co-constructed formulations.

Permission to undertake this study was obtained from the University of Victoria's Human Research Ethics Board (HREB) and the dialogue took place between January 5 and April 13, 2017.

\section{A Note on Terminology}

We find the term "former youth in care" problematic and thus prefer not to use it. We have some discomfort labelling people in terms of what they used to be, and not in terms of who they are now, or may be becoming. As one care leaver stated: "I am not what I went through. I am the courage that escaped, the spark that lit the fires as so many child survivors are" (Wacuka, 2017). In another co-authored paper we wrote with a colleague (Zaharieva, Anglin, \& Rutman, 2017), we experimented with a new term, coined by Lilia — "future anything". While having a more promising tone, this term also has its limitations: can any of us really be anything? We now prefer to speak of young people with lived experiences in care. 
International Journal of Child, Youth and Family Studies (2019) 10(2-3): 25-44

\section{An Inside-Out and Outside-In Dialogue}

Throughout the conversation, we drew upon our respective "careers in care", Lilia having lived in foster homes over a five-year period and having more than a decade of post-care experience, and Jim having run a group home for adolescents and worked in the child and youth care field for over 45 years. In reality, there were many other participants involved indirectly as well, through our engagement with selected books and articles, and our drawing upon interviews from related research projects we had undertaken, singly and jointly, involving young people in care and post-care.

We refer to this dialogue as a conversation involving an "inside-out" (Lilia, as the IO) and an "outside-in" (Jim, as the OI) perspective. An IO, in the context of this paper, is someone who brings deep lived experiences of being removed from their family of origin and placed "in the care of strangers" (Brown \& Seita, 2009). An OI refers to someone who has not lived in care, but who has been involved professionally in working with young people in or from care.

\section{Family Privilege Meets Childhood Trauma}

Jim: Growing up in my family of origin, I experienced stability, parental care, and love from both parents for my entire childhood and adolescence. In fact, we lived in the same house until I was 20 years old. So, in terms of understanding the experience of growing up in care, I have suffered from an absence of pain. In John Seita's words, I have benefitted from "family privilege" (Seita, 2001). Growing up with such privilege and an absence of significant trauma can be obstacles and limitations in terms of understanding childhood pain and pain-based behaviour.

Lilia: Well, I was no stranger to feeling abandoned, neglected, maltreated, and - as I have only recently come to fully realize - unwanted, most of my childhood and adolescence. I was fortunate to spend my earliest years being loved and cared for by grandparents, but after moving from Bulgaria to Canada at five years old my home life seriously deteriorated. I was removed from my family and placed in care at fourteen.

Jim: I appreciate you being willing to dialogue about your childhood and experiences in care, and to reflect on some of the literature related to lived experiences of trauma and living in care. It was important that we have both the okay from your trauma counsellor and HREB approval, but I want you to let me know if, at any time, we need to stop the conversation, take a break, or stop this process altogether — okay?

Lilia: Certainly. But I am really looking forward to this. I feel I am in a good space to reflect on both my own experiences and the notions of pain and pain-based behaviour. I think it might actually help me in my own processing, although I know that is not the purpose of this process.

Jim: Great.... I hope that will be the case, but I want to be careful I don't cross the line from research into counselling.

Lilia: Agreed. 
Jim: Okay. A little background on my child and youth care journey may be helpful. When I was 24 years old, after studying philosophy for five years, I unexpectedly found myself working with adolescents in a mental health centre, never having taken a course on child development, communication, or helping skills. In fact, I didn't even know if I liked or could tolerate children or adolescents. Almost five decades later, I am still struggling to understand what those growing up "in care" want and need from the adults around them. But most of all, I am still struggling to understand myself, to make sense of the injustices of the world, especially those affecting young people. And I am wanting to discover how each of us creates meaning and moves forward within a world of unfathomable pain, whether it is our own pain or the pain of those with whom we live and work.

Lilia: During my years in care, and over more than a decade post-care, I have been involved in various ways, locally, nationally, and internationally, with literally hundreds of youth with lived experience in care. For example, I attended and presented at an IFCO (International Foster Care Organization) conference in Sofia Bulgaria, my birthplace, and at a youth in care conference in Washington, DC. I have found that all too often young people have been placed in the care of the state while too rarely experiencing the feeling of being cared for, or even being cared about. In many cases, these young people have deliberately, even if unwittingly, pushed away the adults charged with their care, thus ensuring a continuation and sometimes escalation of their pain and suffering. I certainly found myself doing this as a survival tactic.

Jim: I think those working with young people in or from care need to be careful not to blame the victim. As you are well aware, such distancing behaviour by youth serves an important purpose. Young people who have suffered various combinations of maltreatment, rejection, loss, abuse and abandonment have every right — and I would add, often a deep need — to push purported helpers away. Why should they trust adults? What evidence do they have that these adults will be any better than those who have already hurt them deeply, and who were supposed to care for and protect them? Helpers must be careful not to blame youth for their pain; their task is to understand and respond in a respectful, caring, and healing manner.

It was precisely to assist helpers to focus on the meaning and origins of young people's aggression, rejection, or withdrawal that I coined the term pain-based behaviour, to counteract such glossing terms as "troubled", "challenging", "misbehaving", "acting out", and the like (Anglin, 2002). We need to recognize and face head-on the legitimate distrust, anger, disappointment, and deep-seated pain of young people at whatever stage in their "care career" they may be. Helpers are often, inadvertently, a part of young people's problems, because we threaten the protective shell they have created to keep themselves from experiencing more hurt, more suffering, more unspeakable pain. It seems to me that his is a central paradox of care work.

Lilia: Yes, and there are no simple formulas for working with young people living in profound psychoemotional pain. In The Primal Wound that we were reading this week, Verrier presents a template for responding to a person in pain (Verrier, 1993). 
International Journal of Child, Youth and Family Studies (2019) 10(2-3): 25-44

Everyone feels " $\mathrm{x}$ "; some [such as you] more than others - this is how, this is why.

The " $x$ " can be filled in with almost any emotion or experience: "everyone feels pain", "everyone thinks of death", "we all feel anger", "we have all felt abandoned", for example. And some, such as youth in care or post-care youth, often feel more pain, more abandonment, more anger, more suicidal than most of us.

Jim: I really like that — that is brilliant! In using this template, or formulation, one begins by normalizing the emotion or experience ("Everyone feels " $\mathrm{x}$ "), then personalizing it ("youth in care such as yourself more than most"), and then completing the response by clarifying how things happen ("this is how") and what may cause these things ("this is why"). Discovering the "how" and "why" of an emotion or experience for a particular youth will likely need to emerge through a process of dialogue, through taking a curious stance; asking, "What do you think happened here?"

Lilia: I hadn't quite conceptualized it that way, but you are right — it is actually quite elegant, and I think could be adapted to many situations and conversations between OIs and IOs.

Jim: I am so glad you shared this. I was actually reading a book last week that had a story in it that I think may be relevant here. Bruce Lipton, in an intriguing book The Biology of Belief (2015), has written movingly about how, in Grade 7, when he was about 12 years old, he first looked through a microscope and was mesmerized when a paramecium swam into view. At that magical moment, a crack in the universe opened to him and he knew he wanted to become a biologist. He also talks about the time, in graduate school, when he first had an opportunity to enter a pitchblack room to look through an electron microscope that allowed him to experience 1,000 times, 10,000 times and even 100,000 times the magnification of his elementary school instrument.

It seems to me, and I wonder what you think, that this story illustrates an important aspect of working with others when one has not lived a similar reality oneself. For example, while each of us has experienced moments of feeling abandoned, by parents, friends, or others, the experiences of abandonment by youth in care may be infinitely greater than many of us blessed with family privilege, such as myself, have experienced.

I actually recall an occasion in my childhood when I was 6 years old, when my very loving parents took my two older sisters (10 and 12 years old) to New York City, from Montreal, for a long Easter weekend. They left me behind with my grandmother. Now, even though she was a lovely person, the recollection of this time still brings up visceral feelings of anger and a sense of outrage at this deep injustice. (“Dammit, I am old enough to come! How dare you leave me behind?”)

In reflecting on this incident, it seems to be the only time in my life when I felt "left behind" or unjustly treated by my parents whose love I never had reason to doubt - even during this challenging long weekend. As an outside-in person trying to understand the experiences of insideouts, I at least had this experience to draw upon from which I can then extrapolate in my mind, my 
International Journal of Child, Youth and Family Studies (2019) 10(2-3): 25-44

imagination, to 10,000 or even 100,000 times magnification in order to have a somewhat better sense of what being an abandoned youth in care might feel like.

Lilia: I think this is a useful analogy. Experiences such as this can perhaps serve as a reminder, or sensitizer, even though such psychological extrapolation — if I can put it that way — is not able to create a truly comparable experience.

\section{Shattered Assumptions}

Lilia: Those who approach youth from the outside-in need to remember that experiences of respect, health, wholeness, efficacy, and joy may be rare for those in care. As Bruce Perry said, in order to create the necessary new brain pathways, youth in and from care need steady and preferably frequent doses of positive experience (Perry \& Szalavitz, 2006).

In Shattered Assumptions, the book you gave me last week, Janoff-Bulman (1992) talks about children needing to develop and maintain their belief in such fundamental assumptions as the benevolence of the world, the meaningfulness of life, and their own self-worthiness. Reading this book has been deeply healing for me, and I have ordered my own copy. It helped me not to take personally some of my rejections. I realized how calcified our language is. Youth who have suffered the effects of abuse or neglect from those supposed to love and protect them often cling desperately to the belief that they are loved and accepted.

Jim: Yes. These fundamental assumptions shape our interpretations of past and present reality as well as our expectations for the future.

Lilia: It may take a great many affirming experiences over an extended period of time to create the new and embedded pathways in the brain that can then interpret sensory inputs in a new way. Bessel van der Kolk, in his book The Body Keeps the Score (2014), stressed the bodily dynamics involved in the internalizing of trauma.

In our conversation last week, we identified a harmful phenomenon that you dubbed "double distortion". I really like this notion. I think it identifies a dynamic that can play a powerful role in keeping those who have experienced complex trauma stuck in negative thinking and self-damaging behaviour patterns.

As I understand it, the first distortion occurs when a young person is maltreated in significant ways. This results in various distorted beliefs and reactions that are then projected onto the world. The second distortion occurs when others react negatively to the expression of distorted behaviours as a result of misunderstanding their origins and meaning, thereby trapping the young person in a downward spiral with no apparent way out.

I have experienced this downward spiral into a vortex of deeper pain; it can feel like being sucked down a sewer. It is painful and frightening, and yet it can also be painful to try to put on the brakes, 
International Journal of Child, Youth and Family Studies (2019) 10(2-3): 25-44

and to start to move back up the whirlpool away from the drain. But I think this is what needs to happen for the process of healing to begin.

\section{Pain and Pain-Based Behaviour}

Jim: When I undertook research into residential care for young people in order to gain a better understanding of whether staffed group homes could be positive for at least some of the youth living in them, one of the major and shocking findings was the profound psycho-emotional, as well as resulting physical, pain experienced by the group home residents - all of them in my study, $100 \%$. As you know, the discovery of such deep-seated and pervasive pain at the heart of group home life and work came in a powerful dream where I woke up after plunging through ice into freezing water. I knew instantly the water represented the pain I had been absorbing viscerally but that had not yet become conscious in my mind. (For an account of this dream, see Anglin \& Scott in this issue.)

Lilia: That is such a powerful story. I could almost feel the freezing cold water, and your terror at feeling like you're drowning. Pain-based behaviour for sure!

Jim: It was this uncovering of the submerged and generally unacknowledged pain being borne by all the children in the research sample that led me to develop the notion of "pain-based behaviour". A new term was needed in order to encourage staff members to see beyond "problem" or "acting out" behaviours and to understand the "inside" of "acting out", which is where the unbearable pain resides. In fact, the central challenge for care work staff is responding to pain and pain-based behaviour. Less effective programs focus on behaviour, and on imposing consequences, sanctions, or punishments on such behaviours - in effect "inflicting pain on pain" (Brendtro \& du Toit, 2005).

Lilia: When I was a teen living in a foster home, one evening a few other under-age friends and I drank too much peach cider. When my social worker found out, she said "Are you ready to be homeless?" There is no more threatening thing you can say to a youth in care. I was confused and angry, with a strong a sense of injustice. I can't make one mistake without being thrown out on the streets? Experimenting with alcohol is such a normal activity at that age, and we all became quite sick - that was consequence enough! And at age 16, I was under pressure to go into independent living — at 16 years old! What child living in their own family is ejected at 16 ?

My foster mum would say things like, "You are so lucky to be here", and, "I don't have the luxury of feeling depressed." I was called self-indulgent for struggling with my emotions, and this drove me back to being a scared animal, like a porcupine, huddling under my quills. Youth in care are very familiar with the look of judgement that comes across people's faces, and that hits us at the core. But helpers also need to beware judging in what they consider positive ways. "You're so strong", "You are so competent", "You are so resilient" — these don't ring true to us. I sometimes wonder whether workers are invoking resilience for their own needs. 
International Journal of Child, Youth and Family Studies (2019) 10(2-3): 25-44

\section{The Evolution of Self while Living "In care" and "Post-care"}

Lilia: Verrier (1993) identifies the development of a "coping self" that young people removed from their families and homes have to create. She maintains that young people in and from care need to uncover their "real selves" that lie buried within them. However, it is not clear to me if such a "real" or "authentic" self was ever developed by many youth in care, especially if the child was removed very early in life or after a life of continual maltreatment.

Verrier also believes that many counsellors are fooled by the "coping self" and encourage their clients to accept and become comfortable with their coping self that is mistaken for a "real self". There are two types of coping selves; a compliant coping self and a defiant coping self, both of which can stifle maturation and the growth or flourishing of one's personality. I know well the dangers of developing a "compliant self", as that was my survival mode throughout most of my childhood. I felt like water; I would take on the shape of any container into which I was poured foster home, classroom, social situation. It was all about surviving, not being a problem. Surviving is surviving, but there is no joy in it.

There is a sense in which the coping self is experienced as an authentic self, as it is the reality of the young person's life as it has evolved to that point. In my early 20s, I committed myself to helping other young people who grew up with a parent experiencing mental illness. I started a program called, interestingly in the context of this conversation, "Inside-Out." I even gave a TEDTalk (TEDxYouth@Victoria, 2012)where I told my own story of growing up with cystic fibrosis, and where I shared some of my struggles, all with humour, of course! I was being as genuine as I could be at that time; I hadn't yet fully realized that I was presenting my coping self, and that there were deeper layers yet to explore.

However, the coping self needs to be faced for what it is, an adaptation to a dysfunctional reality, a survival mechanism, that can keep important parts of one's personality frozen in time. It needs to be freed to grow into a mature sense of identity - into an authentic self. In those days, people liked me more; I was more fun, but I wouldn't trade being authentic for being liked.

Jim: I have watched that YouTube video of your Ted-Talk. You were amazing! Poised, engaging, articulate, and very funny - you commanded the stage and the audience. It seems you have travelled on quite a journey of self-discovery since then.

Lilia: That was quite a moment for me, opening myself up publicly that way.

Jim: According to Robert Kegan (1982), healing from psychoemotional pain is not restoring or retrieving an old or pre-existing self; healing requires evolving from a distorted self into one that allows for more healthy interactions with the environment and with other people (pp. 266-267). We can never restore or recover a previous state of balance; we need to create a new state of harmony in the context in which we are now embedded. Of course, we also may need to change our context, removing ourselves from harmful, toxic relationships or dysfunctional situations, 
International Journal of Child, Youth and Family Studies (2019) 10(2-3): 25-44

whether familial, peer, institutional, or societal. Kegan makes reference to "natural therapy" which occurs when a person is embedded within a healthy environment. He calls what happens in this more healthy or normative context "unselfconscious therapy." Kegan also identifies a bio-socialecological model with a series of interactive domains, or cultures. There is the mothering culture, the parenting culture, the role-recognizing culture (includes school, or work settings), the culture of mutuality (peers, friends, relationships), the culture of self-authorship (experiencing one's own efficacy), and the culture of intimacy (living intimately with another person). A person is embedded in all of these cultures at the same time, and Kegan maintains that each culture has three core functions: confirmation, contradiction, and continuity.

We need from our environment experiences that affirm our value and worth (confirmation), that challenge us to change and grow (contradiction), and that we can count on over time (continuity). The process of development that Kegan describes is reminiscent of Bronfenbrenner's (1979) social-ecological model and his assertion that the process of human development is "the progressive mutual accommodation between the active, growing human being and the changing properties of the immediate settings in which the developing person lives, as this process is affected by relations between these settings, and by the larger contexts in which the settings are embedded" (p. 21).

\section{Moving Beyond Pain-Based Behaviour: Discovering and Seizing the Moments of Choice}

Lilia: I found the book we read last week by the National Youth in Care Network, Pain... lots of pain by Brian Raychaba (1993), quite disturbing. I felt like I was immersed in unprocessed pain. It seems that many research studies and reports involving youth in care engage a sample of young people in interviews, or encourage the young people in some manner to tell their stories. I think stories can be powerful. They can be sensitizing for those wanting to understand the experiences of young people in care, and I think sometimes their telling can be therapeutic for the storytellers themselves. However, there seems to be precious little literature relating stories of the healing process, of moving beyond the pain and pain-based behaviour into living with, in your words, "a sense normality" (Anglin, 2002, pp. 123-132).

Jim: Wonderfully and powerfully put. Unprocessed pain is such a powerful and accurate phrase. It gives me a visceral sensation, and conveys vividly how I also felt reading that book.

Lilia: When I think of healing processes and dynamics, I often think of the profound work of Victor Frankl (1963), the psychiatrist and survivor of the holocaust who developed an approach to healing he termed logotherapy. The Greek word logos can mean both meaning and spirit, both of which pertain to foundational dimensions of the human experience. Frankl believes that people have an intrinsic will to meaning which leads them to strive for understanding about themselves and their place and significance in the world. For Frankl, this is as fundamental as Freud's will to pleasure or a will to survive. I think one of his insights is especially important and relevant for the struggles of young people who live with the effects of trauma. Frankl says: "Between stimulus and response there is a space. In this space, is our power to choose our response. In our response lies 
International Journal of Child, Youth and Family Studies (2019) 10(2-3): 25-44

our growth and our freedom" (quoted in Cochran, 2017, p. 7). I have often been in social situations where I have felt like elevator doors were starting to close, and I had a brief moment to either put my finger in the way or let the doors slam shut.

Jim: This is a powerful image for the experience of this fleeting "space" that Frankl identifies as offering a crucial moment of choice.

Lilia: Yes, and finding choice is such an important part of emerging from a traumatic past, where there was often little or no choice. What Frankl is highlighting is that in every interaction, each of us has the opportunity to make a choice. But first we have to be aware of this space, and then begin to exercise our "choice muscle" that we may have allowed to atrophy, being under the false impression we had no choice, or that our choices would not make a difference. It is true that often we have little or no choice in what happens to us, but Frankl points out that we always have a choice in our attitude towards what happens to us, and in the brief spaces in any interaction, how we choose to respond.

Jim: I realized after our last meeting that although we are reading the same books, we are reading different books. You are reading from the inside-out, from lived experience and with great sensitivity to the experiential implications. I am reading from the outside-in, with a focus on conceptual understanding and practice implications.

Lilia: I like the way you said that. We are reading two different books. I read research like I read a person: do I trust the voice of the researcher?

Jim: I see us as co-researchers, each bringing different but essential aspects to this process.

Lilia: Do you think we might co-produce something? A workshop, an article, or something?

Jim: I think that will come when we have our framework better developed and clarified, when we have a sense of what we might be able to contribute to the field.

\section{Forming or Rebuilding Fundamental Assumptions}

Lilia: I sometimes feel like my bath water is full of babies. When I moved from one placement to another, I didn't know I didn't have to jettison everything. I didn't know it was physically or logically a choice to keep some of my attachments, and not leave them all behind. There was deep, deep, deep shame, lots of shame. [See Bath in this issue for a detailed exploration of shame.]

Jim: It seems negative beliefs need to be challenged through the creation of "cracks" in their seeming intransigence and solidity. Unfortunately, belief in the truth of our mindsets can result in self-fulfilling prophesies and lead to negative consequences that seemingly verify their truth and reality. One of the tasks of helpers is to poke holes in these beliefs, point out contradictory evidence, and demonstrate their exaggerated and self-constructed status. 
International Journal of Child, Youth and Family Studies (2019) 10(2-3): 25-44

Lilia: I sometimes visualize my insides as containing a calcified ball of pain, ugly pain festering inside. In my experience, the mental gymnastics necessary to try to hold on to the fundamental positive beliefs about the world and self can be astounding. I felt the need to maintain these assumptions at all costs, including the convoluted distortions of reality necessary to retain these beliefs. In fact, if we think about the inner struggle of many traumatized young people to hold on to a sense of benevolence, meaning, and worth, it is evident that this process is even more complex than the "double distortion" phenomenon we identified earlier.

Jim: I sometimes think that students with experience in care attending post-secondary education are taking an extra course every term that is invisible, compulsory, and non-credit; namely, dealing with the ongoing effects of trauma.

Lilia: I think of it as like having an "app" running on your cellphone all the time, draining an excessive amount of energy from the battery without you even realizing it. The amount of energy required to deal with the residue of childhood pain can be exhausting!

\section{Emergence from Pain Distortions — Following the Yellow Brick Road}

Jim: Well said; you have such a wonderful way with words and images. So, how do we help young people who have experienced complex trauma to jam their fingers into the closing elevator doors, to experience choice, and to chip away at their calcified pain?

Lilia: Well, it is a journey. In a recent interview, a student who had lived in care said to me: "Well, I'm on the yellow brick road." That image really stuck with me, and I began to think more about Dorothy and the Wizard of Oz (Baum, 1900). I'm actually a huge fan of that book; I even donated to the Smithsonian Institute fundraising campaign to repair and restore a pair of the original red slippers Judy Garland wore in the movie. Dorothy is an orphan of course; she lives with Aunt Em and Uncle Henry when she is swept up in the cyclone.

Jim: You're right! Today we would call that kinship care.

Lilia: And along the yellow brick road, she meets these three characters who are searching for a brain, a heart, and courage. I see it as a metaphor for the journey of youth from care, searching for lost parts of themselves.

Jim: Wonderful! I think you are on to something here. You are reminding me of a powerful quote from Sam Keen who says "the chief function of the teacher is to give students permission to allow exiled portions of their own personalities to return home and be welcomed" (Keen, 1990, p. 68).

Lilia: Perhaps Dorothy was seeking the Wizard, hoping he could make her whole again ... to bring her home to her Self. The last line of the movie is Dorothy back in Kansas saying, “There's no place like home." This oft-repeated phrase is very poignant for youth who have been placed in outof-home care.

Jim: You need to write a book about this. 
International Journal of Child, Youth and Family Studies (2019) 10(2-3): 25-44

Lilia: I have wanted for some time to write about my experiences in various foster home placements, and the title I have in mind is "There's No Place Like Home."

Jim: You must do it! ... when you are ready, of course. This makes me think about the language we use for various forms of living in "out-of-home" care. If a child is adopted, they are chosen. If a child is in foster care, we say they are placed. First Nations youth tell me they were kidnapped, and their parents talk about their children being stolen.

Lilia: For youth in or from care, language is very important.

Jim: We have not talked about Paulo Friere, but as you talk about the power of language, I think of his work in the context of our own dialogue, as well as in relation to being in care.

Lilia: I don't know about Friere.

Jim: I first heard about him back in the 1970s, when I was doing my Master's degree. He wrote a very famous book called Pedagogy of the Oppressed (Friere, 1972). In a nutshell, he talks about teaching illiterate poor people through a process of naming their oppression, for he believed that being able to name your reality is the first step towards changing it. He also points out that one cannot liberate, or empower oneself; nor can one liberate or empower another; we are liberated or empowered only by working together, in solidarity. For his work, he was "invited by the Brazilian government to leave his homeland" (Friere, 1972, book jacket).

Lilia: That makes me wonder ... is there a pedagogy of pain ... and a literacy of pain? Perhaps we need to help young people to name their pain. I once met a woman who had made flash cards because she was having trouble explaining to people, especially doctors, what her pain felt like. For example, she had one that was labelled "popcorn pain".

Jim: Yes, indeed - a literacy of pain. And "popcorn pain" is very evocative. Early on in our conversations, you used the phrase "I was eviscerated!" That word has stuck with me, and evokes a visceral reaction in me.

Lilia: In my experience, it can be difficult for young people to describe their pain; sometimes images can be useful, such as calcified pain, smacked-in-the-face pain, or eviscerated pain, all of which I use, as you know.

I also like Friere's emphasis on solidarity. That is at the heart of the youth in care movement. I spent years in care not knowing any other youth in care. When I discovered the Federation of BC Youth in Care Networks ${ }^{1} \mathrm{I}$ had a new family - I was no longer a struggling alien ... feeling all alone in outer space.

\footnotetext{
${ }^{1}$ See http://fbcyicn.ca/
} 
International Journal of Child, Youth and Family Studies (2019) 10(2-3): 25-44

\section{Stages of Healing: A Tentative Formulation}

Over the course of our dialogue, a tentative outline emerged of the process of healing, of emerging from pain distortions. We identified some elements and dynamics, along with some of the responses that those on the healing journey want or need from those in a position to help.

It is important to note here that these stages are not necessarily experienced in a linear fashion. For example, an individual may experience stage 2 (a sense of normality) before stage 1, when their trauma is truly interrupted. As well, not every person will necessarily experience all of the identified stages as described here. Perhaps another way to understand this framework is that each of these stages represents a dimension of pain and healing, and that an individual may not experience all of these dimensions, or perhaps not in such a sequential fashion. However, we are suggesting that there seems to be a "logic of pain", and that while these dimensions identify what appear to be commonly experienced processes, each person may experience them according to their own "private logic" (Dreikurs, 1973).

What follows is a brief synthesis derived from our many hours of discussion and exploration, drawing on our own experiences, and the readings we undertook together as well as the stories shared with us previously by young people from care. We offer this formulation for your consideration, and as a work in progress.

\section{Stage 1 - Trauma Interrupted}

Early traumatic childhood events occur that elicit psychoemotional (developmental) disruptions and experiential distortions, in a context of partial cognitive development. The result of these experiences is what can be termed distorted introjection. Introjection is the process of internalizing aspects of one's environment, especially the actions of people close to us, and in childhood this happens largely unconsciously without the ability to discern what is healthy and what is distorted.

What is needed from helpers at this stage are caring, loving responses as well as intervention to stop abuse, neglect, or maltreatment, thus creating more positive experiences in a nurturing environment for the child.

\section{Stage $2-A$ Sense of Normality}

At the point that the child is gradually exposed to more normative, positive realities of other children and families, they experience cognitive dissonance; that is, a process of having to shape the new facts to fit the existing distortions. The child struggles to maintain their "assumptive world" (the world is benevolent, life is meaningful, I am worthy) through mental gymnastics.

What the child or youth needs is to experience, and thereby begin internalizing, is a sense of normality. Research by Jim has identified eleven interactional dynamics associated with positive changes in human development (Anglin, 2002, pp. 66-71). In his research over 14 months, across all levels of 10 organizations, Jim noted hundreds of positive changes — from minute to large - 
International Journal of Child, Youth and Family Studies (2019) 10(2-3): 25-44

and each one involved one or more of these dynamics. These are presented below along with some of their potential impacts on youth self-perceptions.

1. Listening and responding with respect to youth helps to develop a sense of dignity, a sense of being valued as persons, and a sense of self-worth.

2. Communicating a framework for understanding helps to develop a sense of meaning and a sense of rationality within daily life.

3. Building rapport and relationships with youth helps to develop a sense of belonging and connectedness with others.

4. Establishing structure, routine, and expectations assists with developing a sense of order and predictability in the world, as well as a sense of trust in the reliability of others.

5. Inspiring commitment in youth encourages the development of a sense of value, loyalty, and continuity.

6. Offering youth emotional and developmental support helps to develop a sense of caring and mastery.

7. Challenging thinking and actions helps youth to develop a sense of potential and capability.

8. Sharing power and decision-making encourages the development of a sense of personal power and discernment.

9. Respecting personal space and time helps youth to develop a sense of independence and autonomy.

10. Discovering and uncovering potential in youth helps develop a sense of hope and opportunity.

11. Providing resources helps develop a sense of gratitude and generosity.

We suggest that any counselling or caring relationship needs to make use of many of these responses on a regular and frequent basis in order to support a healing developmental relationship (Li \& Julian, 2012) and a developmental process over time.

\section{Stage 3 - Shattered Assumptions}

As stage 2 unfolds, there comes a time when major cracks appear in the distorted mental structure, and the distressing reality of the youth's painful past pierces the defences constructed over many years, often leading to discouragement, disillusionment, a sense of hopelessness, and feeling overwhelmed ("I am a monster."; "I am beyond hope.") The task of this stage is facing shattered assumptions.

The response from helpers needs to continue the development of a sense of normality utilizing positive interactional dynamics such as those outlined in stage 2 (above). 
International Journal of Child, Youth and Family Studies (2019) 10(2-3): 25-44

\section{Stage 4 - Masquerade}

If fortunate, the young person starts to connect with others who can offer support and inspire a sense of hope and the potential for a better life, with less pain and suffering ("You can get through this."). At this stage, a mask of normality is created which acknowledges the painful past at a surface level, but leaves the deeper pain hidden and not fully acknowledged. At this point, life is a masquerade and the young person may feel they have "made it" through their pain to a new future. This stage represents a first, but somewhat false, start to healing.

At this juncture, the young person needs someone who can supportively challenge their false self, encouraging them to face difficult and painful realities while offering evidence of hope for a better future ("You have had a painful past, but I have seen you make some good and courageous choices.").

\section{Stage 5 - Cracks in the Façade}

The mask developed in stage 4 can be fragile, and deeper cracks in the façade begin to intrude into consciousness. An increasing awareness of the harsh and unfair reality of what one has lived through, and the internal struggle to face distortions and false beliefs can bring with it a new form of pain. Mixed with the desire to overcome the effects of the original pain is the pain of the struggle to free oneself from the negative impacts and residues of the past. There comes a point when skimming the surface and sugar-coating the least troubling aspects of the past and present, to make them palatable for easy consumption by others, is no longer sufficient. The distortions, in all their ugliness and darkness ("I was born in the mud."; "I am a horrible person.") need to be confronted, and the pursuit of authenticity needs to be understood as more important than the desire to be accepted and liked. This can be a very lonely time. Letting go of a more light-hearted and happy-go-lucky self might mean feeling less loved and accepted, at least by some former friends and acquaintances, and this can be a high price to pay. But perhaps they may reach the point where they are able to say, in Lilia's words, "I wouldn't trade being liked for being authentic."

What youth at stage 5 need from helpers and carers is support and encouragement to face these realities, to recognize the false self they have created, and to keep moving forward with the process of healing and positive development (“It is a painful struggle, but you can get there.”).

\section{Stage 6 - Threshold}

"To face one's demons is a painful journey that involves honestly accepting the 'calcified' pain that has been building up inside in a hard ball for many years" (Lilia). It takes courage, and usually a sensitive and trained confidante or counsellor, to have the strength to keep chipping away at this calcification. At this point, a significant threshold may be reached, when there is a realization that there is no turning back ("You'll never go that low again - you'll have drops, but won't go back as low as you were before.”). While there may be some slippage, two steps forward, one step back, there will not be a return to the deepest darkness encountered at some earlier stages. 
International Journal of Child, Youth and Family Studies (2019) 10(2-3): 25-44

If this stage is successfully navigated, it represents crossing the threshold into a process of genuine growth and development. To be fully successful, it is likely that some form of therapeutic support, such as formal trauma counselling, will need to be provided on an ongoing basis, perhaps for a long time.

\section{Stage 7 - Following the Yellow Brick Road (or The Journey)}

It seems that each stage has its own form of pain and struggle. The next painful stage involves learning to respond to the hurtful and insensitive statements and comments of others, whether in person or indirectly (through the media, in classrooms, in the workplace, etc.). If therapeutic counselling has been underway, there is likely now a greater awareness and sensitivity to the second part of the "double distortion", namely the judgements and labels imposed by others. Once again, youth or young adults can become vulnerable to what they perceive as personal criticism from outside themselves. The temptation is to run and hide, or to do whatever got them through their trauma in the past, but now this is not so easy to do. The cracks in the emotional armour cannot be closed, the glimpses of reality are too powerful to fully ignore, and most importantly, they have developed increased self-awareness and the ability to make healthier choices in their responses.

The task of this stage is learning to face and overcome obstacles to healing and growth, drawing upon the support of both friends and counsellors, as available; youth need companions and mentors to help them continue to progress on the journey along "the yellow brick road."

\section{Stage 8-Flourishing}

The last phase is the ongoing process of growth, and it will have its ups and downs, but without slipping back past the threshold between false start and genuine healing. The central process of this final and likely never-ending stage is flourishing, thanks in large measure to the presence and love of others, even though the deep-seated pain may always be in the background and perhaps flare up again, from time to time.

"What helps most is love. See, it's being ripped from love that causes the wound in the first place, and it's only love in the end that heals it. (Wagamese, 2009, p. 12)

\section{The Importance of Self-Compassion}

Lilia: One other theme that has permeated our dialogue, on my part at least, is the importance of self-compassion. For anyone who has grown up with significant ongoing trauma, it can be difficult to feel compassion for oneself. Often, as I have mentioned frequently, the dominant self-perception is one of disgust, self-loathing, or shame - the results of the introjection of negative messages and emotional rejections. 
International Journal of Child, Youth and Family Studies (2019) 10(2-3): 25-44

It is interesting that the three fundamental assumptions identified by Janoff-Bulman (1992) parallel the three components of the self-compassion learning process that I have been through recently, namely mindfulness, common humanity, and self-kindness [Neff, 2003).

Mindfulness embraces the notion that "This is a moment of suffering", but we need to understand that, overall, the world is benevolent.

Common humanity means that "Suffering is a part of life", but the world, and life, are meaningful.

Self-kindness involves reminding myself "May I be kind to myself”, because I am worthy.

\section{Some Questions Arising}

One day early in our dialogue, Lilia came with an intriguing question that popped into her head on the way to a yoga session: "Is pain-based behaviour a pain-based behaviour?" That was a significant question and offered a new insight into the notion of pain-based behaviour. It raised the question of how someone develops a disposition to react with pain-based behaviour. There are many different forms of pain-based behaviour, such as anger, withdrawing, self-harming, aggression, and so on. How and why are each of these different forms developed by an individual? What is the link between the individual and the specific form their pain-based behaviour takes? Are there also positive pain-based behaviours, such as the development of hyper-vigilance to the subtleties of the behaviours of others, or fierce independence and self-reliance, for example? We now refer to these as "foster kid superpowers". Channeled properly, and in the right contexts, they can be great strengths. Some superpowers, such as valiant isolation, masking one's persona, and trusting no one can become dysfunctional in new contexts and stages of growth. Lilia calls this the cruel paradox of resilience. For example, the very traits that bring youth from care to postsecondary education admission could be holding this group back from the very connections that make the university experience endurable, enjoyable, and successful (For more on this transition, see Zaharieva, Anglin, \& Rutman, 2017).

If there is some validity to the notion that there are stages of healing, such as we have outlined, is it helpful to explore further the different types of therapeutic responses and strategies that may be most appropriate to each stage? Is the notion of a "threshold" in the process of healing from trauma helpful in the counselling or therapeutic process? Does the threshold occur at the same stage in the process for everyone, as we hypothesize, or can it be at different stages for different individuals with different trauma histories, unique living environments, or different constellations of supports? We will not attempt to answer these questions here, but rather offer them for further consideration by other investigators. 
International Journal of Child, Youth and Family Studies (2019) 10(2-3): 25-44

\section{Epilogue}

In addition to writing this article, the two of us carried our dialogue into a 90-minute session at the 2018 National Child and Youth Care Conference in Richmond, BC with about 50 participants. It was an amazing experience for us to expand the conversation in this manner, and we received some encouraging feedback. Perhaps the most powerful was from a woman who had lived in care who said: "I have been reading and reading, searching for years for a framework for understanding my pain. I found that here today." 
International Journal of Child, Youth and Family Studies (2019) 10(2-3): 25-44

\section{References}

Anglin, J. P. (2002). Pain, normality and the struggle for congruence: Reinterpreting residential care for children and youth. New York, NY: Routledge

Anglin, J. P. \& Scott, A. (2019). Researching pain - Re-searching the researcher: Pulling back the curtain on the inner life and anxiety of the investigator. International Journal of Child, Youth and Family Studies, 142-155.

Baum, L. F. (1900). The wonderful Wizard of Oz. Chicago, IL: George M. Hill.

Brendtro, L. K., \& du Toit, L. (2005). Response ability pathways. Cape Town, South Africa: Pretext.

Bronfenbrenner, U. (1979). The ecology of human development: Cambridge, MA: Harvard University Press.

Brown, W. K., \& Seita, J. R. (2009). Growing up in the care of strangers: The experiences, insights and recommendations of eleven former foster kids. Tallahassee, FL: William Gladden Foundation.

Cochran, T. (2017). Focus - From the editor. Parabola: The Search for Meaning, Spring, 7.

Denzin, N. K., \& Lincoln, Y. S. (1994). Handbook of qualitative research. London, UK: Sage.

Dreikurs, R. (1973). The private logic. In H. H. Mosak (Ed.), Alfred Adler: His influence on psychology today (pp. 19-32). Park Ridge, NJ: Noyes Press.

Frank, A. W. (2005). What is dialogical research, and why should we do it? Qualitative Health Research, 15(7), 964-974. doi:10.1177/1049732305279078

Frankl, V. E. (1963). Man's search for meaning: An introduction to logotherapy. New York, NY: Washington Square Press.

Friere, P. (1972). Pedagogy of the oppressed. New York, NY: Herder \& Herder.

Janoff-Bulman, R. (1992). Shattered assumptions: Towards a new psychology of trauma. New York, NY: The Free Press.

Keen, S. (1990) To a dancing god. San Francisco, CA: Harper \& Row.

Kegan, R. (1982). The evolving self: Problem and process in human development. Cambridge, MA: Harvard University Press. 
International Journal of Child, Youth and Family Studies (2019) 10(2-3): 25-44

Li, J., \& Julian, M. M. (2012). Developmental relationships as the active ingredient: A unifying working hypothesis about 'what works' across intervention settings. American Journal of Orthopsychiatry, 82(2), 157-166. doi:10.1111/j.1939-0025.2012.01151.x

Lipton, B. (2016). The biology of belief: Unleashing the power of consciousness, matter and miracles. Carlsbad, CA: Hay House.

Maté, G. (2003). When the body says no: The cost of hidden stress. Toronto, ON: Vintage.

Neff, K. (2003). Self-compassion: An alternative conceptualization of a healthy attitude toward oneself. Self and Identity, 2(2), 85-101. doi:10.1080/15298860309032

Perry, B. D., \& Szalavitz, M. (2006). The boy who was raised as a dog and other stories from a child psychiatrist's notebook. New York, NY: Basic Books.

Raychaba, B. (1993). Pain... lots of pain. Family violence and abuse in the lives of young people in care. Ottawa, ON: National Youth in Care Network.

Seita, J. R. (2001). Growing up without family privilege. Reclaiming Children and Youth, 10(3), $130-132$.

TEDxYouth@Victoria. (2012, January 13). Lilia Zaharieva: Community action from the inside out [Video file]. Retrieved from https://www.youtube.com/watch?v=iAowbxF5zWM

van der Kolk, B. (2014). The body keeps the score: Brain, mind and body in the healing of trauma. New York, NY: Penguin Books.

Verrier, N. N. (1993). The primal wound: Understanding the adopted child. Baltimore, MD: Gateway Press.

Wacuka, R. (2017, June). Violence against children and care expert consultation. Keynote address at the Africa Expert Consultation on Violence against Children in All Care Settings. Retrieved from https://bettercarenetwork.org/sites/default/files/Opening Address by Ruth Wacuka-FINAL.pdf

Wagamese, R. (2009). The Sixties Scoop, the primal wound and home. Canadian Dimension, $43(5), 12$.

Zaharieva, L. M., Anglin, J. P., \& Rutman, D. (2017, March). From a ward to award, and beyond: Supporting former youth in care at the University of Victoria. Report to the Office of Student Affairs, University of Victoria, BC, Canada. 